\title{
FAKTOR YANG MEMENGARUHI PENERAPAN BUILDING INFORMATION MODELING (BIM) DALAM TAHAPAN PRA KONSTRUKSI GEDUNG BERTINGKAT
}

\author{
Nelson $^{1}$, Jane Sekarsari ${ }^{2}$ \\ ${ }^{1}$ Program Studi Sarjana Teknik Sipil, Universitas Tarumanagara, Jl. Letjen S. Parman No.1 Jakarta \\ Email: Nelson.325150058@stu.untar.ac.id \\ ${ }^{2}$ Program Studi Sarjana Teknik Sipil, Universitas Tarumanagara, Jl. Letjen S. Parman No.1 Jakarta \\ Email: tamtana.js@gmail.com
}

\begin{abstract}
ABSTRAK
Salah satu teknologi yang belakangan ini terus berkembang pada sektor industri Arsitektur, Teknik dan Konstruksi adalah Building Information Modeling atau disebut juga BIM. Teknologi BIM tersebut merupakan teknologi yang membantu proses pengerjaan konstruksi bangunan. Negara-negara di Asia Tenggara telah menggunakan teknologi BIM dalam praktik konstruksi, Namun di Indonesia penggunaan teknologi BIM ini masih belum banyak digunakan. Dengan adanya peraturan pemerintah no 2 tahun 2017 pasal 5 ayat 5 yang mengatur tentang pengembangan teknologi yang berkaitan dengan proses pembangunan akan berpengaruh kepada para kontraktor sebagai pelaku jasa konstruksi. Oleh karena itu, studi ini ingin melihat bagaimana kontraktor dalam menjalankan teknologi BIM terutama pada tahapan prakonstruksi. Selain itu ingin mencari faktor pedukung dan penghambat penggunaan teknologi BIM menurut perusahaan kontraktor yang sudah menggunakan teknologi BIM ini. Studi ini dilakukan dengan metode penyebaran kuesioner kepada perusahaan kontraktor yang terlibat dalam penggunaan teknologi BIM terutama di daerah Jakarta. Dari hasil analisis yang dilakukan didapat faktor pendukung yaitu BIM mampu mendeteksi konflik lebih awal dan mampu mencegahnya, BIM membantu dalam penarikan keputusan baik saat perencanaan dan desain, dan Implementasi BIM membangun sinergi antara pemangku kepentingan konstruksi. Selain faktor pendukung ada pula faktor penghambat penggunaan teknologi BIM yaitu keberhasilan individu maupun tim pengguna BIM sangat menentukan keberhasilan proyek dan aplikasi/program yang digunakan tiap orang berbeda-beda sehingga sulit menyatukan informasinya.
\end{abstract}

Kata kunci : Building Information Modeling (BIM), Kontraktor, Prakonstruksi, Faktor Pendukung dan Penghambat

\section{PENDAHULUAN}

Salah satu teknologi pada sector AEC (Architecture, Engineering and Construction) yang tengah berkembang di dunia pada saat ini adalah BIM (Building Information Modeling). Walaupun perkembangan BIM di Indonesia masih belum digunakan secara luas dan merata, namun seiring waktu berjalan dan dengan didukung dengan peraturan pemerintah yang ingin memajukan perkembangan teknologi BIM yaitu UU No. 2 Tahun 2017 tentang Jasa Konstruksi, Pasal 5 Ayat (5). Peraturan tersebut belumlah cukup kuat untuk membuat semua perusahaan menggunakan BIM, namun di waktu yang akan datang mungkin akan ada peraturan lainnya yang lebih kuat dan membuat perusahaan-perusahaan menggunakan teknologi BIM. Oleh karena pesatnya pembangunan tersebut membuat kontraktor sebagai pelaku jasa konstruksi harus bisa menggunakan waktu secara efisien, memberikan kualitas pekerjaan yang baik, dan penggunaan biaya yang seminimal mungkin. Maka dari itu kontraktor harus bisa menemukan konsep/pola pemikiran yang dapat mewujudkan pengerjaan yang efektif dan efisien mulai dari perencanaan maupun pelaksanaannya. Dalam pelaksanaannya di lapangan, dapat kita lihat sering terjadi permasalahan atau konflik, baik dari perubahan desain ataupun terhadap perencanaan logistik. Karena permasalahan-permasalahan tersebut yang membuat terjadinya peningkatan biaya yang seharusnya tidak terjadi dan perbaikannya akan menyita waktu yang lama. Hal tersebut sangat disayangkan karena permasalah-permasalahan yang timbul tersebut akan mengganggu proses aktivitas sebuah konstruksi. Oleh karena itu diperlukan suatu konsep atau pendekatan dalam bidang konstruksi yang memudahkan mengatur berbagai hal agar dapat mengurangi permasalahan-permasalahan tersebut. Pendekatan di bidang teknologi yang sekarang ini sedang dikembangkan adalah Building Information Modeling atau sering disebut juga BIM, merupakan software yang berutujuan membantu proses pengerjaan konstruksi di berbagai bidang. BIM dapat digunakan untuk menunjukkan segala siklus 
hidup bangunan. Siklus hidup yang dimaksud adalah proses konstruksi dan operasi fasilitas. Kuantitas dan kualitas dari suatu material dapat digali dengan mudah. Lingkup kerja dapat dibagi, dipisahkan dan ditentukan.

\section{Daur Hidup Proyek Konstruksi}

Menurut Hafnidar (2016), Konstruksi dapat didefinisikan sebagai tatanan/susunan dari elemen-elemen suatu bangunan yang berkedudukan setiap bagian-bagiannya sesuai dengan fungsinya. Berbiacara tentang konstruksi, maka yang terbayangkan adalah gedung bertingkat, jembatan, bendungan, dam, jalan raya, bangunan irigasi, lapangan terbang dan lain-lain. Secara garis besar tahapan proyek konstruksi dapat dibagi menjadi Tahap Perencanaan (Planning), Tahap Perancangan / desain (Design), Tahap Pengadaan/Pelelangan (Tender), dan Tahap Pelaksanaan (Construction).

\begin{tabular}{|l|l|l|c|}
\hline \multicolumn{2}{|c|}{ PRA KONSTRUKSI } & KONSTRUKSI \\
\hline Tahap Perencanaan & Tahap Perancangan & Tahap Pelelangan & Tahap Pelaksanaan \\
\hline
\end{tabular}

Gambar 1. Tahapan Pra Konstruksi dan Konstruksi

Dari keempat tahapan-tahapan yang disebutkan diatas, tahapan dibagi menjadi 2 bagian, yaitu tahapan pra konstruksi dan konstruksi. Studi yang dilakukan dalam studi ini akan lebih difokuskan pada tahapan pra konstruksi. Dalam tahapan perencanaan dan perancangan para pelaku jasa konstruksi seperti konsultan dan kontraktor, akan dipermudah dengan penggunaan teknologi BIM dalam proses pengerjaannya. Seperti contoh saat menggunakan aplikasi berbasis BIM yang membantu mengetahui secara akurat apabila terjadi konflik pada saat merancang dan mendesain suatu bangunan. Walaupun realisasi pengerjaan di lapangannya belum dikerjakan. Selain itu dalam tahap pelelangan pihak kontraktor pun akan sangat terbantu,hal itu dikarenakan teknologi BIM dapat membantu para kontraktor dalam mengelola keuangan.

\section{Sistem Informasi Manajemen}

Sistem Informasi Manajemen sangat berperan penting baik dalam organisasi maupun bisnis. Sistem informasi manajemen yang baik haruslah menyediakan informasi-informasi yang berguna sebagai umpan balik dalam pelaksanaan operasional, sehingga informasinya berguna bagi manajemen dan pengendalian sistem agar hal-hal yang sudah direncanakan bisa berjalan dengan sesuai. Sistem informasi umumnya terdiri dari berbagai komponen penting yang saling terkait seperti perangkat keras, perangkat lunak, sumber daya manusia, perangkat pendukung dan jaringan. Selain itu sistem informasi juga memiliki batasan seperti adanya fungsi tertentu, modul-modul, beragam aplikasi, departemen dan kelompok pengguna. Suatu sistem informasi manajemen memanfaatkan komponen sebagai berikut:

a. Perangkat keras (hardware)

b. Perangkat lunak (software)

c. Prosedur-prosedur kerja, model, untuk menganalisis melakukan perencanaan pengendalian, dan pengambilan keputusan.

d. Memanfaatkan suatu pangkalan data (database) dan tentunya personal pengelola, serta teknologi informasi.

\section{Building Information Modeling}

Building Information Modeling adalah suatu proses dalam menghasilkan dan mengelola data suatu bangunan selama siklus hidupnya. BIM menggunakan software 3D, real time, dan permodelan bangunan dinamis untuk meningkatkan produktivitas dalam desain dan konstruksi bangunan. Proses produksi BIM meliputi geometri bangunan, hubungan ruang, informasi geografis, serta kuantitas dan kualitan komponen bangunan. BIM dapat digunakan untuk menunjukan segala siklus hidup bangunan seperti proses konstruksi dan operasi fasilitas. Kuantitas dan kualitas dari suatu material dapat digali dengan mudah. Lingkup kerja dapat dibagi, dipisahkan dan ditentukan. BIM digunakan untuk mencapai kemajuan dengan gambar-gambar model dari bagian-bagian sebenarnya yang digunakan untuk membangun suatu gedung. Konsep BIM menggambarkan konstruksi secara virtual sebelum konstruksi fisik yang sebenarnya, untuk mengurangi ketidakpastian, meningkatkan keselamatan, menyelesaikan masalah, mensimulasi dan menganalisa keadaan. BIM juga mencegah kesalahan dengan memungkinkan konflik atau benturan deteksi 
dimana model komputer visual memberikan gambaran kepada tim dimana bagian-bagian dari bangunan seperti misal pipa dan bangunan struktural yang mungkin berpotongan.

\section{Jenis Software Building Information Modeling}

BIM merupakan perangkat lunak yang pada umumnya dimanfaatkan untuk desain dan menghasilkan data yang diperlukan dalam proses konstruksi. Aplikasi BIM menyediakan model gambar yang mengandung banyak informasi. Berikut ini perangkat lunak BIM yang sering digunakan:

Tabel 1. Software BIM (Reinhardt, 2009)

\begin{tabular}{|c|c|c|}
\hline Product Name & Manufacturer & Primary Function \\
\hline Cadpipe HVAC & AEC Design Group & 3D HVAC Modeling \\
\hline Revit Architecture & Autodesk & $\begin{array}{l}\text { 3D Architectural Modeling and } \\
\text { parametric design }\end{array}$ \\
\hline AutoCAD Architecture & Autodesk & $\begin{array}{l}\text { 3D Architectural Modeling and } \\
\text { parametric design }\end{array}$ \\
\hline Revit Structure & Autodesk & $\begin{array}{l}\text { 3D Architectural Modeling and } \\
\text { parametric design }\end{array}$ \\
\hline Revit MEP & Autodesk & 3D Detailed MEP Modeling \\
\hline AutoCAD Civil 3D & Autodesk & Site Development \\
\hline AutoCAD MEP & Autodesk & 3D MEP Modeling \\
\hline Cadpipe Commercial Pipe & AEC Design Group & 3D Pipe Modeling \\
\hline Dprofiler & Beck Technology & $\begin{array}{c}3 D \text { conceptual modeling with real } \\
\text { time cost estimating }\end{array}$ \\
\hline Fastrak & CSC (UK) & 3D Structural Modeling \\
\hline$S D S / 2$ & Design Data & 3D Detailed Structural Modeling \\
\hline $\begin{array}{c}\text { Fabrication for AutoCAD } \\
\text { MEP }\end{array}$ & East Coast CAD/CAM & 3D Detail MEP Modeling \\
\hline
\end{tabular}

\section{Manfaat BIM}

BIM dapat mendukung dan meningkatkan praktik bisnis industri Architect Engineer and Construction (AEC). Menurut Jason dan Umit (2010) BIM sangat bermanfaat dalam bidang konstruksi salah satunya saat tahapan desain. Manfaat BIM saat mendesain

a. Visualisasi desain yang lebih akurat

b. Tingkat koreksi tinggi ketika membuat perubahan desain

c. Menghasilkan gambar 2D yang akurat dan konsisten disetiap tahap desain

d. Beberapa kolaborasi disiplin desain

e. Memudahkan pemeriksanaan terhadap desain

f. Memperkirakan biaya selama tahap desain

g. Meningkatkan efisiensi energi dan keberlanjutan

\section{BIM Bagi Kontraktor}

Dalam proses pembangunan konstruksi yang belum menggunakan BIM , terutama dalam proses desain sering kali tidak mengikutsertakan kontraktor dalam pembuatannya. Hal tersebut membatasi kemampuan kontraktor dalam mengkontribusikan pengetahuan mereka pada saat proses desain, yang memungkinkan para kontraktor mampu menambahkan hal yang penting.

Dalam dari BIM of Handbook, BIM mampu memberikan keuntungan mengenai kebutuhan kontraktor, yang dapat diaplikasikan seperti :

1. Analisis konstruksi dan deteksi mengenai konflik ataupun hambatan

2. Pengestimasian Biaya maupun kuantitas/jumlah

3. Perencanaan dalam pembangunan/konstruksi

4. Intergrasi mengenai biaya dan control penjadwalan serta fungsi manajemen lainnya

5. Verifikasi, pentunjuk, dan pengecekan dalam aktivitas konstuksi 


\section{Peraturan Pemerintah Terkait BIM}

BIM sejauh ini sudah mulai digunakan beberapa perusahan kontraktor. Namun masih banyak perusahaan yang belum menggunakan pula, hal ini terkait dengan peraturan pemerintah yang sedikit terkait dengan penggunaan teknologi yang berguna membantu proses pembangunan. Hasil studi pustaka, menemukan peraturan yang terkait penggunaan BIM bagi perusahaan-perusahaan jasa konstruksi yaitu: UU No. 2 Tahun 2017 tentang Jasa Konstruksi , Pasal 5 Ayat (5) Yang berbunyi "Pemerintah Pusat memiliki kewenangan mengembangkan standar material dan peralatan konstruksi serta inovasi teknologi konstruksi”. Oleh karena peraturan yang telah ditetapkan tersebutlah yang membuat perusahaan jasa konstruksi kedepannya diharapkan sudah menggunakan teknologi konstruksi dalam proses pelaksanaan konstruksinya.

\section{METODOLOGI PENELITIAN}

\section{Konsep Penelitan}

Penelitian ini menggunakan kuesioner sebagai cara untuk mengumpulkan data yang diinginkan. Skala yang digunakan pada kuesioner yang dibuat yaitu skala Likert yang merupakan skala yang umum dalam penggunaannya untuk penyusunan kuesioner. Setelah disusun, kuesioner tersebut disebarkan ke beberapa perusahaan kontraktor, orang-orang yang berkaitan langsung dengan teknologi BIM yang menjadi responden. Dari hasil pengisian kuesioner oleh responden maka data dapat terkumpul yang selanjutnya akan dianalisis dengan beberapa pengujian statistik dengan menggunakan bantuan program statistik untuk mendapatkan faktor pendukung dan penghambat bagi penggunaan teknologi BIM. Setelah dianalisis kemudian dibuat pembahasan mengenai hasil analisisnya. Barulah setelah hasil analisis, dapat diambil kesimpulan dan saran.

\section{Diagram Alir Penelitian}

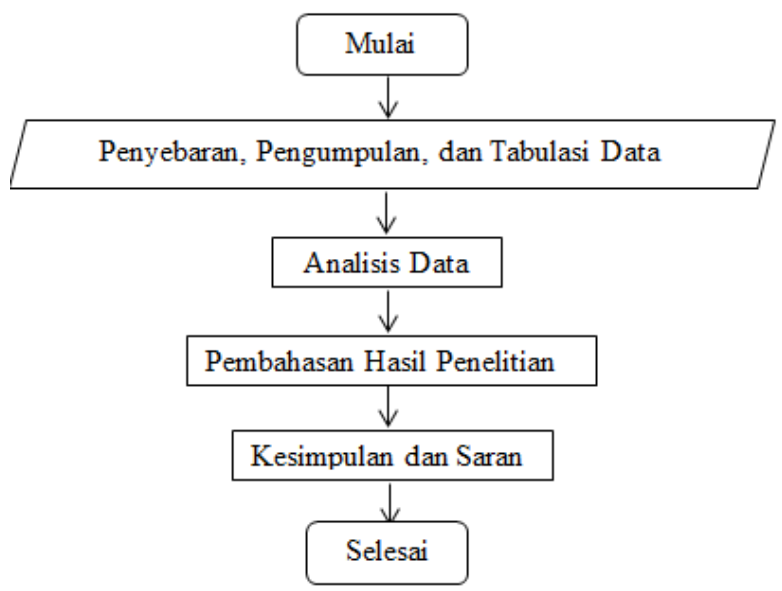

Gambar 2. Diagram Alir Penelitian

\section{Faktor Pendukung}

Dengan studi pustaka yang dilakukan sebelumnya didapat variabel untuk faktor pendukung penerapan teknologi BIM yang akan digunakan dalam kuesioner dan dianalisis sebagai berikut:

$\mathrm{X} 1$ = BIM mampu mendeteksi konflik/kesalahan lebih awal dan mampu mencegahnya

X2 = BIM mampu mendisiplinkan kinerja perusahaan maupun proyek

X3 = BIM mampu membagikan informasi secara lengkap dan cepat

X4 = BIM membantu peningkatan komunikasi sehingga kesalahan dapat diminimalkan

X5 = BIM membantu dalam penarikan keputusan baik saat proses perencanaan dan desain

X6 = BIM mempermudah proses modeling desain bentuk bangunan baik 2D maupun 3D

X7 = BIM mempermudah manajemen barang, uang dan pekerjaan

X8 = Penggunaan Teknologi BIM membantu membangun kepercayaan dan mengurangi risiko

X9 =Implementasi BIM membangun sinergi antara pemangku kepentingan konstruksi (owner, kontraktor, konsultan,dsb) 


\section{Faktor Penghambat}

Dengan studi pustaka yang dilakukan sebelumnya didapat variabel untuk faktor penghambat penerapan teknologi BIM yang akan digunakan dalam kuesioner dan dianalisis sebagai berikut:

X10 = Mahalnya harga lisensi aplikasi yang berbasis BIM

X11 = Dibutuhkan spesifikasi hardware yang bagus untuk menggunakan aplikasi BIM

$\mathrm{X} 12$ = BIM kurang mampu mendetailkan gambar dengan skala yang cukup kecil

X13 = Individu yang masih kurang pemahamannya terhadap penggunaan aplikasi BIM

X14 = Aplikasi / Program yang digunakan tiap orang berbeda-beda sehingga sulit menyatukan informasinya

X15 = Keberhasilan Individu maupu tim pengguna BIM sangat menentukan keberhasilan proyek

X16= Berbeda Program yang digunakan membuat individu yang menggunakan memerlukan pelatihan terus menerus

X17 = Diperlukan pengambilan keputusan saat mendesain 3D modeling menggunakan BIM sehingga Drafter/ Teknisi CAD akan sulit menggunakannya

X18 = Data yang dicari oleh kontraktor saat ini masih berbentuk 2D belum menggunakan 3D

\section{ANALISIS DAN PEMBAHASAN}

\section{Analisis Data}

Data yang diterima hasil penyebaran kuesioner yang telah dikumpulkan akan diuji secara validitas dan reliabilitas. Data kuesioner itu diuji karena ingin dicari faktor pendukung dan penghambat yang lolos dari uji validitas dan reliabilitas.

\section{Pengujian Validitas}

Uji Validitas dilakukan agar diketahui apakah suatu instrumen valid atau tidak. Faktor Pendukung yang akan diuji secara validitas berjumlah 9 variabel, dengan jumlah data yang diteliti sebanyak $25(\mathrm{n}=25)$ dan probabilitas $5 \%$ maka bila dilihat dari tabel nilai $r$ akan didapat nilai $r$ sebesar 0,396. Hasil dari Uji Validitas Variabel Faktor Pendukung dapat dilihat pada tabel 2. Dan Hasil dari Uji Validitas Variabel Faktor Penghambat dapat dilihat pada tabel 3.

Tabel 2. Hasil Output Pengujian Validitas Faktor Pendukung

\begin{tabular}{|c|c|c|c|c|c|c|c|c|c|c|c|}
\hline \multicolumn{12}{|c|}{ Correlations } \\
\hline & & $\mathrm{X}_{1}$ & $X_{2}$ & $x_{3}$ & $x_{4}$ & $\times 5$ & $\times 8$ & $x 7$ & $X_{8}$ & $\times 9$ & Score \\
\hline \multirow[t]{3}{*}{$\overline{X 1}$} & Pearson Correlasion & 1 & 299 & .597 & 300 & 519 & .070 & .036 & .631 & .503 & 786 \\
\hline & Sig. (2-tailed) & & .146 & .002 & .144 & .008 & .741 & .865 & .001 & .010 & .000 \\
\hline & N & 25 & 25 & 25 & 25 & 25 & 25 & 25 & 25 & 25 & 25 \\
\hline \multirow[t]{3}{*}{$\times 2$} & Pearson Comelation & 299 & 1 & .400 & .053 & -191 & .296 & -110 & .162 & 510 & .443 \\
\hline & Sig-(2-tailed) & .145 & & .047 & .801 & .359 & .152 & .602 & .438 & .009 & .027 \\
\hline & N & 25 & 25 & 25 & 25 & 26 & 26 & 25 & 25 & 26 & 25 \\
\hline \multirow[t]{3}{*}{$\times 3$} & Pearson Correlation & 597 & $.400^{\circ}$ & 1 & .107 & .412 & .009 & .083 & $.550^{-}$ & .386 & $.699^{-}$ \\
\hline & Sig. (2-tailed) & .002 & .047 & & .811 & .041 & .965 & .694 & .004 & .057 & .000 \\
\hline & N & 25 & 25 & 25 & 25 & 26 & 26 & 25 & 25 & 25 & 25 \\
\hline \multirow[t]{3}{*}{$x 4$} & Pearson Cortelason & 300 & .053 & 107 & 1 & 5352 & $.116^{\circ}$ & .000 & $.071^{\circ}$ & 206 & .500 \\
\hline & Sig. (2-tailed) & .144 & .801 & .611 & & .006 & .682 & 1.000 & .736 & .323 & .011 \\
\hline & $\mathrm{N}$ & 25 & 25 & 25 & 25 & 25 & 25 & 25 & 25 & 25 & 25 \\
\hline \multirow[t]{3}{*}{$\times 5$} & Pearson Correlason & 519 & -191 & .412 & $.532^{-}$ & 1 & .070 & .125 & $.508^{-1}$ & 247 & $689^{\circ}$ \\
\hline & Sig-(2-tailed) & .008 & .359 & .041 & .006 & & .741 & .551 & .010 & 234 & .000 \\
\hline & N & 25 & 25 & 25 & 25 & 25 & 25 & 25 & 25 & 25 & 25 \\
\hline
\end{tabular}


Faktor yang Memengaruhi Penerapan Building

Nelson, et al. Information Modeling dalam Tahapan Pra Konstruksi

Gedung Bertingkat

Tabel 2. Hasil Output Pengujian Validitas Faktor Pendukung (Lanjutan) Correlations

\begin{tabular}{|c|c|c|c|c|c|c|c|c|c|c|c|}
\hline & & $\mathrm{X}_{1}$ & $\times 2$ & $\times 3$ & $x_{4}$ & $\times 5$ & $\times 6$ & $x 7$ & $x_{8}$ & $\times 9$ & Score \\
\hline \multirow[t]{3}{*}{$\overline{\times 6}$} & Pearson Correlston & $7.070^{2}$ & 235 &., 00 & 1.916 & $.07 \%$ & 7 & $0 \infty$ & $2.244^{2}$ & $\overline{.05}$ & 1.166 \\
\hline & Sig. $(2$-tailed $)$ & .741 & .162 & .05 & $.6 \% 2$ & .741 & & $m$ & 169 & .638 & .460 \\
\hline & $N$ & 25 & 26 & 25 & 25 & 26 & 26 & 25 & 25 & 25 & 26 \\
\hline \multirow[t]{3}{*}{$\bar{x}$} & Pearson correlson & का &., $710^{\circ}$ & .005 & $\infty$ & $1266^{\circ}$ & का० & 7 & -.524 & $126^{\circ}$ & 266 \\
\hline & Seg. (2-tailed) & .965 & 602 & 694 & 1.000 & .651 & 777 & & .055 & 600 & .190 \\
\hline & $N$ & 25 & 25 & 25 & 25 & 25 & 26 & 25 & 25 & 25 & 26 \\
\hline \multirow[t]{3}{*}{$\bar{x} \theta$} & Pearson correlsson? & 691 & .162 & $.660^{\circ}$ & .071 & .506 & -.284 & -.124 & 1 & .369 & $.698^{\circ}$ \\
\hline & Sig- (2-tailed) & $\infty 1$ & .498 &.$\infty 4$ & 736 & .010 & 169 & SSS & & .054 & .002 \\
\hline & $N$ & 25 & 25 & 25 & 25 & 25 & 26 & 25 & 25 & 25 & 26 \\
\hline \multirow[t]{3}{*}{$\overline{x 9}$} & Pearsoncomelsoon & .6003 & 610 & .395 & 206 & 247 & -.099 & .126 & 369 & 1 & .673 \\
\hline & Sig. (2-tailed) & .010 &.$\infty 09$ & .087 & $32 n$ & 234 & 699 & .560 & .054 & & $\infty \infty$ \\
\hline & $N$ & 25 & 25 & 25 & 25 & 25 & 26 & 25 & 25 & 25 & 26 \\
\hline \multirow[t]{3}{*}{$\begin{array}{l}\text { Th } \\
\text { al }\end{array}$} & Pes/soncorelasion & 760 & .443 & $.699^{-}$ & .600 & 669 & .165 & 266 & .690 & 673 & 1 \\
\hline & Sig. (2-tailed) &.$\infty 00$ & .027 & .000 & 011 & .000 & .460 & .190 & .002 & .000 & \\
\hline & $N$ & 25 & 25 & 25 & 25 & 25 & 26 & 25 & 26 & 25 & 26 \\
\hline
\end{tabular}

Tabel 3. Hasil Output Pengujian Validitas Faktor Penghambat

\begin{tabular}{|c|c|c|c|c|c|c|c|c|c|c|c|}
\hline \multicolumn{12}{|c|}{ Corr } \\
\hline & & $\times 10$ & $\mathrm{X} 11$ & $\mathrm{X} 12$ & $\mathrm{X} 13$ & $\times 14$ & $\mathrm{X} 15$ & $\times 16$ & $\times 17$ & $\mathrm{X} 18$ & Total \\
\hline \multirow[t]{3}{*}{$\overline{x 10}$} & Pears on Correlation & $T$ & .574 & .040 & 224 & .026 & -100 &. .001 &. .277 & .2359 & 334 \\
\hline & Sig-(2.tsiled) & &.$\infty 03$ & .849 & 281 & .901 & .633 & .701 & .180 & .249 & .103 \\
\hline & N & 25 & 25 & 26 & 25 & 25 & 25 & 25 & 25 & 25 & 25 \\
\hline \multirow[t]{3}{*}{$\overline{X 11}$} & Pesrson Correlastion & .574 & $\overrightarrow{1}$ & .184 & 191 & .022 & .069 & .0 .03 & $-.112^{\circ}$ & .271 & 396 \\
\hline & Sig-(2-tailed) & .000 & & 380 & 361 & .917 & .742 & .694 & .594 & .190 & .050 \\
\hline & $\mathrm{N}$ & 25 & 25 & 25 & 25 & 25 & 25 & 25 & 25 & 25 & 25 \\
\hline \multirow[t]{3}{*}{ 'X12 } & Pears on Correlation & $-.040^{4}$ & .184 & $T^{*}$ & -.044 & .171 & .453 & $-.088^{\circ}$ & $-106^{\circ}$ & 329 & .475 \\
\hline & Sig. (2-tailed) & .849 & .390 & & .835 & .415 & .023 & .676 & .614 & .109 & .016 \\
\hline & N & 26 & 25 & 25 & 25 & 25 & 26 & 26 & 25 & 25 & 25 \\
\hline \multirow[t]{3}{*}{$\mathrm{X} 13$} & Pears on Correlation & $224^{-}$ & .191 & .044 & 1 & $235^{\circ}$ & .031 & .292 & .144 & .236 & 369 \\
\hline & Sig. (2-tailed) & .281 & 361 & .835 & & .252 & .882 & .156 & .493 & .251 & .055 \\
\hline & $N$ & 25 & 25 & 25 & 25 & 25 & 25 & 25 & 25 & 25 & 25 \\
\hline \multirow[t]{3}{*}{ 'x14 } & Pesrson Corretaston & .06 & .022 & .171 & $238^{\prime}$ & 1 & .628 & .276 & 468 & .991 & 706 \\
\hline & Sig-(2-tailed) & .901 & .917 & .415 & .252 & &.$\infty 1$ & .181 & .018 & 361 & .000 \\
\hline & $\mathrm{N}$ & 25 & 25 & 25 & 25 & 25 & 25 & 25 & 25 & 25 & 25 \\
\hline \multirow[t]{3}{*}{ 'X15 } & Pears on Corretation & $-100^{\circ}$ & .069 & 453 & .031 & .628 & 1 & $-.063^{\circ}$ & 223 & 392 & $67 / 4$ \\
\hline & Sig-(2-tsiled) & .633 & .742 & .023 & 882 &.$\infty 1$ & & .766 & 286 & .052 &.$\infty 0$ \\
\hline & N & 25 & 25 & 26 & 26 & 25 & 25 & 25 & 26 & 26 & 26 \\
\hline \multirow[t]{3}{*}{ X16 } & Pearson Correlation & $-.081^{\circ}$ & .083 & -.088 & -292 & $-.276^{-}$ & .063 & 1 & .039 & $.125^{\prime}$ & .013 \\
\hline & Sig. (2-tailed) & .701 & 694 & .676 & .156 & .181 & .766 & & .852 & .552 & .952 \\
\hline & N & 25 & 25 & 25 & 25 & 25 & 25 & 25 & 25 & 25 & 25 \\
\hline \multirow[t]{3}{*}{ 'X17 } & Pearson comelation & .277 & -.112 & .506 & .144 & .468 & 223 & .039 & 1 & .123 & $365^{\circ}$ \\
\hline & Sig-(2-tailed) & .100 & .694 & .614 & 499 & ond & 286 & .862 & & .000 & .072 \\
\hline & N & 25 & 26 & 25 & 26 & 25 & 26 & 26 & 26 & 25 & 26 \\
\hline \multirow[t]{3}{*}{ Xर18 } & Pearsonconetastion - & .239 & -271 & .329 & .258 & 19 & 392 & $.126^{\circ}$ & .123 & 1 & $326^{\circ}$ \\
\hline & Sig. (2-tailed) & .249 & .190 & .106 & .251 & .361 & .062 & .662 & .660 & & .111 \\
\hline & $N$ & 25 & 26 & 26 & 25 & 25 & 26 & 26 & 25 & 25 & 26 \\
\hline \multirow[t]{3}{*}{ 'Thal } & Pearson Correlation & 334 & 396 & $475^{\circ}$ & $389^{\circ}$ & 706 & $674^{m}$ & -0.013 & $365^{2}$ & 326 & $\overrightarrow{1}$ \\
\hline & Sig- (2-tailed) & .103 & .060 & 016 & .065 & .000 &.$\infty 0$ & .962 & .072 & .111 & \\
\hline & N & 26 & 26 & 25 & 25 & 25 & 26 & 25 & 25 & 25 & 26 . \\
\hline
\end{tabular}

Dari hasil pengujian validitas untuk faktor pendukung dan faktor penghambat, diambil nilai Pearson Correlation yang melewatin nilai r tabel yaitu 0.396. untuk dapat dilanjutkan ke pengujian berikutnya. 


\section{Pengujian Reliabilitas}

Uji Reliabilitas penelitian ini akan dilakukan dengan metode Alpha Conbranch's. Metode tersebut mengacu pada nilai alpha yang akan dianalisis dan dihasilkan dari software terapan statistik (SPSS) dibandingkan dengan syarat agar nilai yang diuji dapat dikatakan reliabel. Hasil output untuk nilai uji reliabilitas dari faktor pendukung dapat dilihat pada tabel 4 dan hasil output untuk nilai uji reliabilitas dari faktor penghambat dapat dlihat pada tabel 5

Tabel 4. Hasil Output Pengujian Reliabilitas Faktor Pendukung

\begin{tabular}{rcrc} 
& \multicolumn{2}{c}{ Reliability Statistics } \\
\cline { 2 - 3 } & $\begin{array}{c}\text { Cronbach's } \\
\text { Alpha }\end{array}$ & N of Items \\
\cline { 2 - 3 } & \multicolumn{2}{c}{.786} & \\
\cline { 2 - 3 } & \multicolumn{2}{c}{ Item-Total Statistics } & \\
\hline Scale Mean if & Variance if & Corrected & Cronbach's \\
Item Deleted & Item Deleted & Correlation & Alpha if Item \\
& Deleted \\
\hline 15.92 & 6.327 & .746 & .723 \\
16.52 & 5.260 & .609 & .730 \\
16.44 & 5.090 & .515 & .779 \\
16.16 & 5.890 & .674 & .718 \\
16.56 & 6.090 & .448 & .782 \\
\hline
\end{tabular}

Tabel 5. Hasil Output Pengujian Reliabilitas Faktor Penghambat

Reliability Statistics

\begin{tabular}{c}
\hline $\begin{array}{c}\text { Cronbach's } \\
\text { Alpha }\end{array} \quad$ N of Items \\
\hline $.770 \quad 2$ \\
Item-Total Statistics
\end{tabular}

\begin{tabular}{lrrrr}
\hline & $\begin{array}{r}\text { Scale Mean if } \\
\text { Item Deleted }\end{array}$ & $\begin{array}{c}\text { Scale } \\
\text { Variance if } \\
\text { Item Deleted }\end{array}$ & $\begin{array}{c}\text { Corrected } \\
\text { Item-Total } \\
\text { Correlation }\end{array}$ & $\begin{array}{c}\text { Cronbach's } \\
\text { Alpha if ltem } \\
\text { Deleted }\end{array}$ \\
\hline X14 & 3.48 & .677 & .628 & \\
X15 & 3.32 & .810 & .628 & \\
\hline
\end{tabular}

Pada pengujian reliabilitas dipilih variabel-variabel yang memiliki nilai Corrected Item-Total Correlation lebih besar dari nilai $r$ tabel yaitu 0.396. Apabila masih ada variabel yang memiliki nilai Corrected Item-Total Correlation dibawah nilai 0.396 maka variabel tersebut akan dikeluarkan dan dilakukan pengujian reliabilitas ulang tanpa variabel tersebut. Dari hasil pengujian validitas dan reliabilitas pada faktor pendukung pengunaan teknologi BIM yang semula berjumlah 9 variabel hanya 5 variabel yang berhasil memenuhi pengujiannya yaitu variabel X1, X3, X5, X8, dan X9. Dan dari hasil pengujian validitas dan reliabilitas pada faktor penghambat penggunaan teknologi BIM yang semula berjumlah 9 variabel hanya 2 variabel yang memenuhi kedua pengujiannya yaitu variabel X14 dan X15.

\section{KESIMPULAN}

Dari hasil analisis dan pembahasan di bab yang sebelumnya, didapat kesimpulan sebagai berikut:

1. Dari hasil analisis yang dilakukan, didapat 5 faktor pendukung penggunaan teknologi BIM yaitu

a. BIM mampu mendeteksi konflik/kesalahan lebih awal dan mampu mencegahnya.

b. BIM mampu membagikan informasi secara lengkap dan cepat

c. BIM membantu dalam penarikan keputusan baik saat proses perencanaan dan desain.

d. Penggunaan Teknologi BIM membantu membangun kepercayaan dan mengurangi risiko. 
e. Implementasi BIM membangun sinergi antara pemangku kepentingan konstruksi (owner, kontraktor, konsultan, dsb)

2. Dari hasil analisis yang dilakukan, didapat 2 faktor penghambat pengunaan teknologi BIM yaitu

a. Keberhasilan individu maupun tim pengguna BIM sangat menentukan keberhasilan proyek

b. Aplikasi / Program yang digunakan tiap orang berbeda-beda sehingga sulit menyatukan informasinya.

3. Pada studi ini mendukung penelitian terdahulu (Rayendra,2014) yang menyatakan keuntungan atau faktor yang mendukung penggunaan teknologi BIM adalah meminimalkan desain lifecycle dengan meningkatkan kolaborasi antar owner, konsultan, dan kontraktor. Namun pada studi ini, didapat 3 faktor pendukung yang paling dominan adalah BIM mampu medeteksi konflik/kesalahan lebih awal dan mampu mencegahnya, BIM membantu dalam penarikan keputusan baik saat proses perencanaan dan desain, dan Implementasi BIM membangun sinergi antara pemangku kepentingan konstruksi (owner, kontraktor, konsultan, dsb).

\section{DAFTAR PUSTAKA}

Eastman C.,et.al. (2011). "BIM of Handbook : Guide to Building Information Modeling for Owners, Managers, Designer, Engineers, and Contractors”. Hoboken:John \& Sons,inc

Hafnidar, Rani A. (2016), ”Manajemen Proyek Konstruksi”.Yogyakarta: Deepublish,

Jason U. and Umit I., (2011). "Handbook of Research Building Information Modeling for Owner, Managers, Designers, Engineers, and Contractors”.Hoboken:John \& Sons,inc.

Rayendra dan Biemo, W. D. (2014). "Studi Aplikasi Teknologi Building Information Modelling untuk PraKonstruksi”. Teknik Sipil dan Lingkungan Universitas Institut Teknologi Bandung, Bandung.

Reinhardt. BIM Authoring Tools. Tersedia di https://www.researchgate.net/figure/BIM-Authoring-Tools-Reinhardt2009_fig21_253058808. Diakses pada tanggal 8 Maret 2019

Sekarsari, J., SISTEM INFORMASI MANAJEMEN: Teori dan Konsep Aplikasi pada Sektor Konstruksi, Jakarta: Universitas Trisakti, 2018 